\title{
Kynurenine Pathway Metabolites as Biomarkers for Amyotrophic Lateral Sclerosis
}

\author{
Vanessa X. Tan and Gilles J. Guillemin* \\ Macquarie University Centre for MND Research, Department of Biological Sciences, Faculty of Medicine and Health \\ Sciences, Macquarie University, Sydney, NSW, Australia
}

\section{OPEN ACCESS}

Edited by:

Pierre-francois Pradat,

Hôpitaux Universitaires Pitié

Salpêtrière, France

Reviewed by:

Veronica Perez De La Cruz,

National Institute of Neurology

and Neurosurgery (INNN), Mexico

Stephanie Marie-Rose Duguez,

Ulster University, United Kingdom

Anne-Sophie Rolland,

Institut National de la Santé et de la

Recherche Médicale (INSERM),

France

*Correspondence:

Gilles J. Guillemin

gilles.guillemin@mq.edu.au

Specialty section:

This article was submitted to

Neurodegeneration,

a section of the journal

Frontiers in Neuroscience

Received: 01 July 2019

Accepted: 06 September 2019

Published: 20 September 2019

Citation:

Tan VX and Guillemin GJ (2019) Kynurenine Pathway Metabolites as Biomarkers for Amyotrophic Lateral Sclerosis. Front. Neurosci. 13:1013.

doi: 10.3389/fnins.2019.01013
Amyotrophic Lateral Sclerosis (ALS) currently lacks a robust and well-defined biomarker that can 1) assess the progression of the disease, 2) predict and/or delineate the various clinical subtypes, and 3) evaluate or predict a patient's response to treatments. The kynurenine Pathway (KP) of tryptophan degradation represent a promising candidate as it is involved with several neuropathological features present in ALS including neuroinflammation, excitotoxicity, oxidative stress, immune system activation and dysregulation of energy metabolism. Some of the KP metabolites (KPMs) can cross the blood brain barrier, and many studies have shown their levels are dysregulated in major neurodegenerative diseases including ALS. The KPMs can be easily analyzed in body fluids and tissue and as they are small molecules, and are stable. KPMs have a Janus face action, they can be either or both neurotoxic and/or neuroprotective depending of their levels. This mini review examines and presents evidence supporting the use of KPMs as a relevant set of biomarkers for ALS, and highlights the criteria required to achieve a valid biomarker set for ALS.

Keywords: kynurenine pathway, amyotrophic lateral sclerosis, biomarker development, neurodegeneration, motor neuron disease, neuroinflammation and neurodegeneration, tryptophan

\section{AMYOTROPHIC LATERAL SCLEROSIS}

The diagnosis of amyotrophic lateral sclerosis (ALS) can only be fully confirmed by the post mortem detection of ALS-associated protein inclusions such as TDP-43 and SOD1 (Turner et al., 2013). Coupled with the spectrum of symptoms seen in the clinical presentation of ALS, the diagnosis of ALS relies on presentation to a neurologist and the elimination of other neurological and/or muscular diseases such as Kennedy's disease or myasthenia gravis, based on the El Escorial criteria that requires the assessment of disease progression (Brooks et al., 2000; Lambrechts et al., 2007; AlChalabi et al., 2016; Hardiman et al., 2017). This results in the average time from onset of symptoms after diagnosis of ALS being 10 months, in a disease with survival of 24-48 months (Chiò et al., 2009; Hardiman et al., 2017).

Abbreviations: 3HAA, 3-hydroxyanthranilic acid; 3HK, 3-hydroxykynurenine; 5-HT, serotonin; AA, anthranilic acid; ALS, amyotrophic lateral sclerosis; $\mathrm{BBB}$, blood brain barrier; $\mathrm{BH} 4$, tetrahydrobiopterin; ChAT, choline acetyltransferase; CNS, central nervous system; CSF, cerebrospinal fluid; GCMS, gas chromatography mass spectrometry; HPLC, high performance liquid chromatography; IHC, immunohistochemistry; KP, kynurenine pathway; KPM, KP metabolites; KTR, kynurenine: tryptophan Ratio; KYN, kynurenine; KYNA, kynurenic acid; LC-MS/MS, liquid chromatography tandem mass spectrometry; MS, multiple sclerosis; NAD+, nicotinamide adenine dinucleotide; NMDA, $N$-methyl-D-aspartate; PIC, picolinic acid; QUIN, quinolinic acid; QUINA, quinaldic acid; SOD1, Cu/Zn superoxide dismutase; TRP, tryptophan; XA, xanthurenic acid. 
Defined as characteristic that is objectively measured and evaluated as an indicator of normal biological process, pathogenic process, or a pharmacogenomic process to therapeutic intervention, biomarkers include genomics, proteomics, metabolomics, neurophysiology, and neuroimaging (Ganesalingam and Bowser, 2010; Turner et al., 2011). The lack of a reliable biomarker for ALS hampers a rapid, definitive diagnosis of disease, determination of ALS subtypes, monitoring of disease progression in patients, and limits the ability of clinicians and scientists to achieve an unbiased assessment of the efficiency of new treatments (Turner et al., 2009; Ganesalingam and Bowser, 2010). For patients and their families, a sensitive and specific biomarkers could allow detection of ALS at early stages, and allow the prognosis of the clinical subtype of ALS to predict disease aggressivity and subtype (Ganesalingam and Bowser, 2010; Al-Chalabi et al., 2016). This research gap in biomarker discovery and development for ALS comes not only as an impediment for patients and their families, but also at a cost to the pharmaceutical industries, through the monitoring of drug effects and disease progression in clinical trials. In particular, the repeated failure of drugs demonstrating clinical efficacy, and the inability to detect improvements, or non-improvements rapidly (Aggarwal and Cudkowicz, 2008; Ganesalingam and Bowser, 2010; Petrov et al., 2017).

\section{THE KYNURENINE PATHWAY}

One of the hallmarks of ALS is the presence of neuroinflammation and the kynurenine pathway (KP) is known to be strongly induced by inflammatory cytokines such as IFN- $\gamma$ (McGeer and McGeer, 2002; Moffett and Namboodiri, 2003; Chen et al., 2010; Oxenkrug, 2011). The KP is the major route of tryptophan (TRP) catabolism, and feeds into the serotonin pathway, immune related tetrahydrobiopterin (BH4) pathway, glycolysis, and de novo nicotinamide adenine dinucleotide (NAD+) pathway (Figure 1) (Stone, 1993; Grant et al., 2010; Oxenkrug, 2013; Sasaki, 2019); linking it to fatigue, depression, inflammation, and decrease in energy metabolism (Sandyk, 2006; Grant et al., 2010; Oxenkrug, 2013).

The essential amino acid tryptophan originates from the diet, if which up to $85 \%$ is bound to albumin in blood circulation, and 99\% metabolized in the liver (Quagliariello et al., 1964; Yuwiler et al., 1977; Badawy, 2017). Activation of the $\mathrm{KP}$ is achieved by the triggering of the first enzyme of the pathway, indoleamine 2,3 dioxygenase (IDO1) (Guillemin et al., 2005c; Badawy, 2017). This results in the production of several neuroactive metabolites such as the excitotoxins quinolinic acid (QUIN), and 3-hydroxykynurenine (3HK) by activated monocytic cells (Guillemin et al., 2003b); and the neuroprotective kynurenic acid (KA) and picolinic acid (PIC) by astrocytes and neurons, respectively (Heyes et al., 1988; Beninger et al., 1994; Guillemin et al., 2001, 2007; Badawy, 2017). The KP is active in most cell types, particularly in the liver (Takikawa et al., 1986; Heyes et al., 1997), and is highly activated in monocytic cells during inflammation (Jones et al., 2015). Only a limited number of KP can cross the blood brain barrier (BBB). TRP, Kynurenine (KYN), 3HK, anthranilic acid (AA) are actively transported by the large neutral amino acid carrier system; and others via passive diffusion (Fukui et al., 1991; Ruddick et al., 2006). This indicates that peripheral activation of the KP by inflammation can be translocated to the central nervous system (CNS), altering immune regulation and increasing neurotoxicity (Owe-Young et al., 2008). In the CNS, most cells contain the complete set of KP enzymes, and are capable of degrading TRP (Guillemin et al., 2005c; Lee et al., 2017). However, neurons, astrocytes and oligodendrocytes are incapable of synthesizing QUIN, only activated microglia and infiltrating macrophages produce QUIN (Guillemin et al., 2000; Lim et al., 2007).

The concept of using kynurenine pathway metabolites (KPMs) as markers for diseases dates back to the 1950s (Musajo et al., 1955; Tompsett, 1959), where excretion of KPMs were observed in the urine of patients diagnosed with cancer, rheumatoid arthritis, cardiovascular events and fevers (Musajo et al., 1955; Takahashi et al., 1956; Tompsett, 1959; McMillan, 1960; McManus and Jackson, 1968; Mawatari et al., 1995). More recently, the KP is investigated mostly in other liquid biopsies such as serum and plasma (Lewitt et al., 2013). The levels of the KPMs has been shown to be well correlated between the cerebrospinal fluid (CSF) and blood (Curzon, 1979; Chen et al., 2010; Myint, 2012; Jacobs et al., 2019), however, they are not always identical; and only few studies (Curzon, 1979; Widner et al., 2002; Chen et al., 2010; Zuo et al., 2016; Havelund et al., 2017; Lim et al., 2017; Jacobs et al., 2019) correlate the $\mathrm{KP}$ levels in different biofluids from the same patients at the same time. KPMs have been historically measured using thin layer chromatography, and detected under UV light, or via radioactive metabolites (Musajo et al., 1955, 1956; McMillan, 1960; McManus and Jackson, 1968; Shibata, 1988). Today, KPMs are more often measured using more sensitive methods and equipment such as high performance liquid chromatography (HPLC), Gas chromatography mass spectrometry (GCMS), and liquid chromatography tandem mass spectrometry (LC-MS/MS) (Heyes and Markey, 1988; Bizzarri et al., 1990; Smythe et al., 2003; de Jong et al., 2009; Pedersen et al., 2013; Miller et al., 2018). The most commonly measured KPMs are TRP, KYN, and KYNA, and are often presented as ratios. As they are small molecules, the KPMs such as KYN, KYNA, Xanthurenic acid (XA) and AA have been shown to be stable. With the exception of 3-hydroxy anthranilic acid (3HAA), which is known to be particularly unstable over time and sensitive to light (Darlington et al., 2010; Midttun et al., 2014).

Ex vivo, the KPMs have been measured using immunohistochemistry (IHC) in tissue sections (Guillemin et al., 2005a; Steiner et al., 2011; Lim et al., 2013). More recently, techniques such as tissue-based Matrix-assisted laser desorption/ionization (MALDI) Mass spectrometry Imaging (MSI) and tissue microarray has been used to not only detect, but localize the presence of TRP and KYN in tumors ex vivo (Puccetti et al., 2015; Ait-Belkacem et al., 2017). This specific localization will allow for focal observation of KPMs changes within tissue, and targeted applications of monitoring and altering of the KP if this can be translated in vivo. 


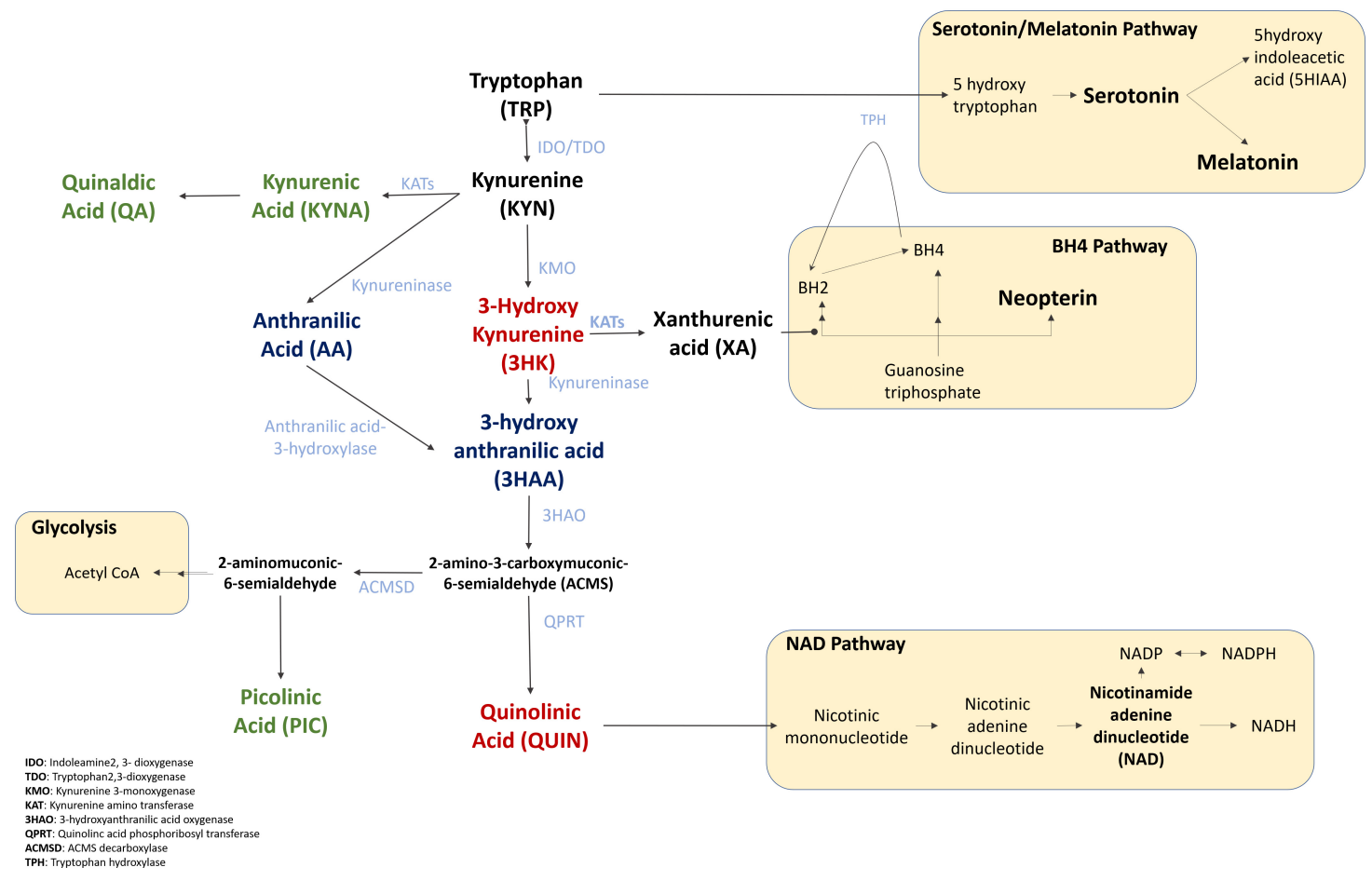

FIGURE 1 | The Kynurenine Pathway and its downstream pathways of Serotonin/Melatonin, BH4, Glycolysis, and NAD+. Tryptophan is converted into serotonin and melatonin, that regulate mood and sleep. The tetrahydrobiopterin ( $\mathrm{BH} 4$ ) pathway interacts with the KP in three ways, (1) the sharing of the enzyme TPH that degrades tryptophan, (2) the inhibition of a key BH4 pathway enzyme, sepiapterin reductase, (3) both BH4 and KP are induced by inflammatory cytokines. Tryptophan also feeds into the glycolysis cycle via ACMS, affecting ATP production. Finally, the KP is the de novo synthesis pathway of NAD+ which is associated with cellular energy, repair and fatigue. The key KPMs are bolded, neurotoxic metabolites represented in red, neuroprotective metabolites in green, and dual functioning in blue.

Using the levels of KPMs, the activity of their associated enzymes can be derived as a proxy of the concentrations of direct derivatives of the metabolites as a ratio (Darlington et al., 2007; Sathyasaikumar et al., 2011; Lim et al., 2013) - most commonly measuring IDO1 via the Kynurenine: Tryptophan ratio (K/T ratio; KTR); or via direct enzymatic assays (Sathyasaikumar et al., 2011). Although few studies have looked at the direct correlation between metabolite ratio and enzymatic concentrations (Baran et al., 1999).

In vitro, neurotoxic KPMs such as QUIN and $3 \mathrm{HK}$, have been shown to induce neurodegeneration and neuronal cell death through excitotoxicity, $N$-methyl-D-aspartate (NMDA) receptor antagonism, increased glutamate release, and the production of reactive oxygen species (Kim and Choi, 1987; Koh and Choi, 1988; Khaspekov et al., 1989; Nakagami et al., 1996; Shoki et al., 1998; Guidetti and Schwarcz, 1999; Leipnitz et al., 2007; Guillemin, 2012b; Kalonia et al., 2012; Pierozan et al., 2015). The neurotoxic mechanisms of QUIN is well established, and overlaps with mechanisms of neurodegeneration in ALS such as excitotoxicity, hyperphosphorylation, and protein dysfunction (Pierozan et al., 2010; Guillemin, 2012a; Lee et al., 2017). Some of the KPMs such as KYNA, PIC, and 3HAA have neuroprotective and immunomodulatory properties (Foster et al., 1984; Behan and Stone, 2000; Grant et al., 2009; Krause et al., 2011; LugoHuitrón et al., 2011). Other KPMs such as 3HAA, have both neurotoxic and neuroprotective functions depending on their relative concentrations (Colín-González et al., 2013; PérezGonzález et al., 2017). The KPMs can influence each other levels (Perkins and Stone, 1982; Jhamandas et al., 1990), and the balance of KPMs is crucial for managing the equilibrium between neurotoxicity and neuroprotection. The dysregulation of KPMs, especially excessive QUIN production, has been correlated with variations of other neuroinflammatory markers (Heyes et al., 1992; Guillemin et al., 2003a; Kalonia et al., 2011), making the modulation of KPMs a plausible target for the regulation of the immune response within the CNS (Stone et al., 2012; Bohár et al., 2015; Jacobs and Lovejoy, 2018).

Using these modern techniques, the KP has been investigated as a marker for progression, severity, and prognostic for diseases such as systemic lupus erythematosus (Perl, 2015; Åkesson et al., 2018), cancers (Jin et al., 2015; Zuo et al., 2016; Xie et al., 2017; Huang et al., 2018; Liu et al., 2018; Khan et al., 2019), cardiovascular disease (Sun et al., 2013; Zuo et al., 2016), lung cancer and chronic obstructive pulmonary disease (Chuang et al., 2014; Zinellu et al., 2018), chronic kidney disease and diabetes (Hirayama et al., 2012; Zhao, 2013), acquired immunodeficiency syndrome (AIDS) and HIV-dementia (Fuchs et al., 1990; Heyes et al., 1991; Sardar et al., 2002; Guillemin et al., 2005b; Favre et al., 2010; Lee et al., 2016; Wang et al., 2019), pancreatic cysts (Park et al., 2013), acute myeloid leukemia and lymphomas 
(Giusti et al., 1996; Finger et al., 2017), vitamin levels (Midttun et al., 2014), tuberculosis (Weiner et al., 2012; Feng et al., 2015), malaria (Medana et al., 2003), irritable bowel syndrome (IBS) (Clarke et al., 2012; Gupta et al., 2012), rheumatoid arthritis (Spiera and Vallarino, 1969; Schroecksnadel et al., 2003), growth deficits (Kosek et al., 2016), obesity (Mangge et al., 2014), and preeclampsia (Nilsen et al., 2012). In the nervous system, the KP has been shown to associate with pathologies such as stroke (Darlington et al., 2007), schizophrenia (Müller and Schwarz, 2006; Kegel et al., 2014; Oxenkrug et al., 2016), Parkinson's (Ogawa et al., 1992; Widner et al., 2002; Lewitt et al., 2013; Havelund et al., 2017), neuropsychiatric disorders such as depression and stress (Mackay et al., 2009; Gabbay et al., 2010; Olsson et al., 2010; Steiner et al., 2011; Kocki et al., 2012; Erhardt et al., 2013; Comai et al., 2016; Küster et al., 2017; Huang et al., 2018; Kuwano et al., 2018), suicide (Erhardt et al., 2013; Bay-Richter et al., 2015; Brundin et al., 2016), multiple sclerosis (Rejdak et al., 2002; Lim et al., 2017), Alzheimer's disease (Guillemin et al., 2005a; Hartai et al., 2007), Huntington's disease (Schwarcz et al., 1988; Beal et al., 1990; Stoy et al., 2005; Byrne and Wild, 2016), brain tumors (Adams et al., 2012, 2014), Autism Spectrum Disorders, and Attention Deficit Hyperactivity Disorder (ADHD) (Aarsland et al., 2015; Bryn et al., 2017). More recently, studies have demonstrated that the KPMs could be used for the prognosis of MS, and also to differentiate between disease subtypes (Aeinehband et al., 2015; Lim et al., 2017).

\section{AMYOTROPHIC LATERAL SCLEROSIS AND KYNURENINE-ASSOCIATED PATHWAYS}

The levels of KPMs are known to be dysregulated in the serum, CSF, and tissue of ALS patients (Ilzecka et al., 2003; Chen et al., 2010) (Table 1). The first study by Ilzecka et al. (2003) investigated the presence of KYNA in ALS patients and matching healthy controls. Broadly, the results did not show any significant differences in the levels of KYNA between patients and controls in either serum or CSF. However, CSF KYNA was higher in (1) patients with severe clinical status; and (2) in patients with bulbar onset, compared to patients with limb onset. The authors concluded that this increase likely associated with the neuroprotective role of KYNA. The authors also showed that the concentrations of KYNA in CSF and in serum were not correlated, indicating that KYNA in the CNS is mostly produced in the brain by astrocytes (Guillemin et al., 2001), and this confirms that KYNA is able to cross the BBB and may be imported from the PNS. This is supported by the presence of astrogliosis as part of the neuroinflammatory features found in ALS brain. In 2010, our team reported increased levels of TRP, KYN, and QUIN in both CSF and serum. This study did not investigate KYNA or astrogliosis as Ilzecka et al. did, however, does confirm the neuroinflammatory status in ALS patients, with presence of activated microglia and activation of the KP in the motor cortex.

Other studies have indirectly reported associations between ALS and the KPMs. Jhamandas et al. (1990) showed that injections of the excitotoxin QUIN and 3HAA, directly into the rat brain, triggers a decrease in choline acetyltransferase (ChAT) activity, and that KYNA, PIC, quinaldic acid (QUINA), and AA co-injections could antagonize the QUIN-induced neurotoxicity. In addition, QUIN injections were associated with neuronal loss, but also glial proliferation, highlighting the important roles played by KPMs in neuroinflammation and glial activation in ALS.

Aside from the KP, tryptophan is also metabolized by pinealocytes into serotonin (5-HT), and then melatonin, a serotonin downstream metabolite. Pinealocytes are external to the $\mathrm{BBB}$, and thus directly affected by the KP in the periphery, but not directly by the KP in the CNS (Ruddick et al., 2006). Within the brain, serotonin is modulated by tryptophan levels. A decrease in serotonin levels has been linked to depression through tryptophan depletion (Owens and Nemeroff, 1994; Ruddick et al., 2006; Maes et al., 2011), and with the decrease of melatonin, and sleep disturbances, which are both symptoms in ALS patients (Sandyk, 2006). Furthermore, motoneurons affected in ALS are heavily innervated by serotoninergic neurons; whereas those resistant to ALS-associated degeneration are less innervated by serotonin neurons, possibly linking serotonin with induction of neuronal excitability and neurodegeneration. The roles of serotonin in ALS has been reviewed (Sandyk, 2006). Melatonin has been shown to confer neuroprotection in ALS patients and $\mathrm{Cu} / \mathrm{Zn}$ superoxide dismutase (SOD1) mice models, likely by decreasing systemic oxidative stress, caspase activation, and by increasing ATP availability to increase cell repair mechanisms to limit neuronal death (Weishaupt et al., 2006; Zhang et al., 2013).

The metabolic pathway of tryptophan degradation also feeds into the cell's energy metabolism through the production of $\mathrm{NAD}+$ and glycolysis. Its dysregulation increases the risk for the development of neurodegenerative diseases as many repair and neuroprotective systems perform at a suboptimal level. NAD+ depletion can lead to fatigue (Procaccini et al., 2016; Camandola and Mattson, 2017; Sasaki, 2019). Altered energy metabolism has also been investigated in ALS (Dupuis et al., 2004; Ngo and Steyn, 2015), and has been shown to be altered by QUIN via the respiratory chain and Krebs cycle (Ribeiro et al., 2006; Colín-González et al., 2015). The NAD+ pathway represents an important therapeutic avenue, and is being targeted using precursors such as nicotinamide phosphoribosyl transferase, or nicotinamide ribosyl directed at ageing, neurodegeneration, and in particular, axonal degeneration (Sasaki et al., 2006; Imai and Yoshino, 2013; Verdin, 2015; Pehar et al., 2018).

A pathway that has been understudied in ALS is the tetrahydrobiopterin (BH4) pathway (Figure 1). Interconnected to the KP via the modulatory effect of XA, and as a co-substrate for tryptophan hydroxylase (Zhang et al., 2006; Cronin et al., 2018), studies on BH4 have largely focused on inflammation, pain and neuroprotection (Oxenkrug, 2007; Ghisoni et al., 2015; Cronin et al., 2018). BH4 is strongly associated with neuroinflammation, and is also an essential co-factor in nitric oxide synthases in oxidative stress (Sakai et al., 1995; Guix et al., 2005; Cronin et al., 2018) - both pathological features present in ALS. Several reports have associated $\mathrm{BH} 4$ with neurodegeneration, such as the differential methylation of $\mathrm{BH} 4$ 
TABLE 1 | Summary of Kynurenine Pathway metabolite levels in controls and ALS patients collated from Ilzecka and Chen.

\begin{tabular}{|c|c|c|c|c|c|c|}
\hline \multirow[t]{2}{*}{ References } & \multirow[t]{2}{*}{ KPM } & \multirow[t]{2}{*}{ Population } & \multirow[t]{2}{*}{ Serum } & \multirow[t]{2}{*}{ CSF } & \multicolumn{2}{|c|}{ Trend observed } \\
\hline & & & & & Serum & CSF \\
\hline & & $\operatorname{ALS}(n=16)$ & $57.8 \pm 35.0$ & $1.59 \pm 0.9$ & Mild $>$ Severe & Control < Bulbar \\
\hline & & Bulbar $(n=6)$ & $59.5 \pm 39.3$ & $3.61 \pm 2.0$ & Control > Severe & Bulbar > Limb \\
\hline & & $\operatorname{Limb}(n=10)$ & $59.6 \pm 31.2$ & $1.70 \pm 1.0$ & clinical status & Control $<$ Severe \\
\hline \multirow[t]{20}{*}{ Chen } & $\operatorname{TRP}(\mu \mathrm{M})$ & Control $(n=17)$ & $75.0 \pm 10.5$ & $2.58 \pm 0.16$ & Control < ALS** & Control < ALS** \\
\hline & & $\operatorname{ALS}(140)$ & $143.3+5.6$ & $5.0 \pm 0.2$ & & \\
\hline & & $\operatorname{sALS}(n=133)$ & $133.3 \pm 6.0$ & $4.67 \pm 0.19$ & & \\
\hline & & fALS $(n=7)$ & $166.4 \pm 20.7$ & $5.20 \pm 0.87$ & & \\
\hline & & Bulbar $(n=31)$ & $128.2 \pm 10.6$ & $4.58 \pm 0.33$ & & \\
\hline & & $\operatorname{sALS}(n=133)$ & $4.05 \pm 0.21$ & $0.22 \pm 0.01$ & & \\
\hline & & fALS $(n=7)$ & $3.24 \pm 0.36$ & $0.26 \pm 0.05$ & & \\
\hline & & Bulbar $(n=31)$ & $3.99 \pm 0.29$ & $0.22 \pm 0.02$ & & \\
\hline & & $\operatorname{Limb}(n=109)$ & $4.00 \pm 0.24$ & $0.21 \pm 0.03$ & & \\
\hline & $\mathrm{PIC}(\mu \mathrm{M})$ & Control $(n=35)$ & $2.4 \pm 0.4$ & $0.51 \pm 0.11$ & Control > ALS* & Control $>$ ALS $(p=0.09)$ \\
\hline & & $\operatorname{ALS}(140)$ & $1.4+0.1$ & $0.36+0.03$ & & \\
\hline & & SALS $(n=133)$ & $1.46 \pm 0.13$ & $0.35 \pm 0.07$ & & \\
\hline & & fALS $(n=7)$ & $1.80 \pm 0.51$ & $0.60 \pm 0.21$ & & \\
\hline & & Bulbar $(n=31)$ & $1.45 \pm 0.16$ & $0.30 \pm 0.06$ & & \\
\hline & & $\operatorname{Limb}(n=109)$ & $1.49 \pm 0.10$ & $0.35 \pm 0.07$ & & \\
\hline & QUIN ( $\mu \mathrm{M})$ & Control $(n=35)$ & $0.30 \pm 0.03$ & $0.038 \pm 0.004$ & Control < ALS* & Control < ALS* \\
\hline & & sALS $(n=133)$ & $0.04 \pm 0.00$ & $0.04 \pm 0.00$ & & \\
\hline & & fALS $(n=7)$ & $0.02 \pm 0.00$ & $0.04 \pm 0.01$ & & \\
\hline & & Bulbar $(n=31)$ & $0.04 \pm 0.00$ & $0.04 \pm 0.00$ & & \\
\hline & & $\operatorname{Limb}(n=109)$ & $0.04 \pm 0.00$ & $0.04 \pm 0.00$ & & \\
\hline
\end{tabular}

Mild clinical status defined as mild to moderate according to Munsat, Severe clinical status defined as severe to terminal according to Munsat. KMP, KP metabolites; Kyna, Kynurenic acid; TRP, tryptophan; KYN, kynurenine; PIC, picolinic acid; QUIN, quinolinic acid; IDO, indoleamine dioxygenase; KVT ratio, kynurenine/tryptophan ratio; sALS, sporadic ALS; fALS, familial ALS. * $p<0.05 ;{ }^{*} p<0.0001$.

in monozygotic twins discordant for ALS (Young et al., 2017); and particularly in Parkinson's Disease (Choi et al., 2004; Foxton et al., 2007; Yoon et al., 2010).

With all these evidences associating the KP in ALS, especially the unbalance between neuroprotective and neurotoxic metabolites, the KPMs represent a relevant set of biomarkers to characterize disease subtypes and to assess disease progression. As mentioned previously, such biomarkers are lacking especially for the response to treatments and for testing new drugs in clinical trials. One of the main reasons supporting the role of KPMs as a biomarker for ALS is its association with neuroinflammation. The KTR (indication of IDO activity, and thus KP activation) is a very sensitive and specific marker for inflammation. This KTR ratio is well suited as a surrogate progressive, or end-point marker for neuroinflammation. Apart from CSF, body fluids such as blood and urine are easiest to collect. Measurement of KPMs levels in blood present a rapid and reliable set of markers as there are validated quantification methods, and they are stable. However, there are still some limitations using the KPMs as a biomarker for diseases.

Firstly, a potential pitfall using the KPMs as a biomarker for neurological diseases and psychological disorders is that $\mathrm{KP}$ activation is not specific of one disease as it is present in all neuroinflammatory diseases. Thus, the KP cannot be used a 
diagnostic marker, but is relevant as a prognostic/progression marker, and to identify disease subtypes. Diagnostically, the KPMs still have a great potential as a confirmatory biomarker in conjunction with a shortlisted clinical diagnosis, or subtype. For example in MS, we were able to differentiate MS subtypes from patients diagnosed with MS (Lim et al., 2017). Similarly, when a patient is suspected to have ALS, or has been diagnosed with ALS by a neurologist, the KPMs can be used to differentiate between disease subtypes (e.g., bulbar or lower motor neuron symptoms) and be able to differentiate between patients predicted to be fast or slow progressors. The addition of other inflammatory markers such as cytokines, chemokines, C Protein Reactive, etc, in combination with KPMs would increase the sensitivity and specificity of the biomarker set.

Secondly, the biological functions of all the KPMs are not fully understood - it is a very complex system that is intertwined other regulatory pathways such as BH4 (Cronin et al., 2018), and ultimately regulate the immune system. Further, there is only a limited direct correlation between enzymatic activities and the metabolite formation and their ratios. This is not a key issue in using the KP as surrogate biomarkers, as the crux is that the KPM ratios (ratios of the bioactive metabolites) are what confer biological activity and biomarker association; rather than the function of measuring the enzyme activity. The levels of KPMs in the general population has been directly investigated by Zuo et al. (2016) $(n=7015)$ and Gostner et al. (2015) $(n=100)$, which showed that some KPMs are influenced by both age (KTR, KYN, HAA), and gender (TRP) (de Bie et al., 2016a,b). Further, tryptophan has been shown to increase through to adolescence (Lepage et al., 1997) and in adulthood (Mangge et al., 2014). An earlier study by Medana et al. (2003) investigated the KPMs in Malawian children and Vietnamese adults who were affected by Malaria, showing that increases in QA and PIC in both populations could predict a fatal outcome. On the contrary, differences in KA levels in Malawian children as compared to Vietnamese adults (Medana et al., 2003), although it is unclear if this difference was attribute to age, disease, or ethnicity. Further, the correlation of the KPMs in different biofluids need to be better established for correlation and pathway studies. Urine represents the ideal biofluid as it is non-invasive. However, it is not homeostatic, and apart from early studies when the KP was discovered in urine (Musajo et al., 1955, 1956; Tompsett, 1959; McMillan, 1960; Mawatari et al., 1995), only few recent studies have analyzed the KPMs in urine (Fukuwatari et al., 2004; Pedersen et al., 2013; Dolina et al., 2014). Recent research mostly use serum or plasma to assess the KPMs (Darlington et al., 2007; Favre et al., 2010;

\section{REFERENCES}

Aarsland, T. I. M., Landaas, E. T., Hegvik, T.-A., Ulvik, A., Halmøy, A., Ueland, P. M., et al. (2015). Serum concentrations of kynurenines in adult patients with attention-deficit hyperactivity disorder (ADHD): a case-control study. Behav. Brain Funct. 11:36. doi: 10.1186/s12993-015-0080-x

Adams, S., Braidy, N., Bessesde, A., Brew, B. J., Grant, R., Teo, C., et al. (2012). The Kynurenine pathway in brain tumor pathogenesis. Cancer Res. 72, 5649-5657. doi: 10.1158/0008-5472.CAN-12-0549
Hirayama et al., 2012; Aarsland et al., 2015; Comai et al., 2016; Oxenkrug et al., 2016; Lim et al., 2017), and some when available, CSF (Erhardt et al., 2013; Havelund et al., 2017; Sühs et al., 2019). Further, the KP has been proposed as therapeutic intervention for neurodegenerative diseases such as ALS, and has been well reviewed (Füvesi et al., 2012).

As for other potential candidate biomarkers for ALS, the need for defined classifications of ALS subtypes or stages of disease progression (Gil et al., 2017) is critical. Standardized operation procedures for a defined analysis of progression rate, imaging, biopsy retrieval and storage, and biomarker analysis techniques need to be implemented to ensure consistency across centers to achieve an objective assessment. Biobanks storing clinical and biopsies of patient and control samples will be crucial to achieving the aim of a clinically applicable biomarker for ALS.

\section{CONCLUSION}

Overall, the KPMs have potential to be used as a sensitive and specific biomarker for patients diagnosed with ALS. Such markers would also have the ability to be used for surrogate clinical and prognostic biomarkers as we previously demonstrated for MS (Lim et al., 2017) and Alzheimer's disease (Chatterjee et al., 2018; Jacobs et al., 2019). The strong correlation of the KP with neuroinflammation, depression, and immune regulation makes it a valid candidate as a surrogate biomarker for ALS, for disease progression (fast/slow progressors) and possibly disease subtyping. Combining the KPM levels together with (1) other markers of inflammation or neurodegeneration, (2) clinical information, and (3) imaging would strongly increase both sensitivity and specificity of the biomarker set.

\section{AUTHOR CONTRIBUTIONS}

VT wrote the first draft of the manuscript. Both authors contributed to manuscript revision and read and approved the submitted version.

\section{FUNDING}

This research was supported by the MND Research Institute of Australia, FightMND, CreAte ALS Association, and Macquarie University.

Adams, S., Teo, C., McDonald, K. L., Zinger, A., Bustamante, S., Lim, C. K., et al. (2014). Involvement of the Kynurenine pathway in human glioma pathophysiology. PLoS One 9:e112945. doi: 10.1371/journal.pone.011 2945

Aeinehband, S., Brenner, P., Ståhl, S., Bhat, M., Fidock, M. D., Khademi, M., et al. (2015). Cerebrospinal fluid kynurenines in multiple sclerosis; relation to disease course and neurocognitive symptoms. Brain Behav. Immun. 51, 47-55. doi: 10.1016/j.bbi.2015. 07.016 
Aggarwal, S., and Cudkowicz, M. (2008). ALS drug development: reflections from the past and a way forward. Neurotherapeutics 5, 516-527. doi: 10.1016/j.nurt. 2008.08.002

Ait-Belkacem, R., Bol, V., Hamm, G., Schramme, F., Van Den Eynde, B., Poncelet, L., et al. (2017). Microenvironment tumor metabolic interactions highlighted by qMSI: application to the Tryptophan-Kynurenine pathway in immunooncology. SLAS Discov. 22, 1182-1192. doi: 10.1177/2472555217712659

Åkesson, K., Pettersson, S., Ståhl, S., Surowiec, I., Hedenström, M., Eketjäll, S., et al. (2018). Kynurenine pathway is altered in patients with SLE and associated with severe fatigue. Lupus Sci. Med. 5:e000254. doi: 10.1136/lupus-2017-000254

Al-Chalabi, A., Hardiman, O., Kiernan, M. C., Chiò, A., Rix-Brooks, B., and van den Berg, L. H. (2016). Amyotrophic lateral sclerosis: moving towards a new classification system. Lancet Neurol. 15, 1182-1194. doi: 10.1016/S14744422(16)30199-5

Badawy, A. A. (2017). Kynurenine pathway of tryptophan metabolism: regulatory and functional aspects. Int. J. Tryptophan. Res. 10:1178646917691938. doi: 10. $1177 / 1178646917691938$

Baran, H., Jellinger, K., and Deecke, L. (1999). Kynurenine metabolism in Alzheimer's disease. J. Neural Transm. 106, 165-181.

Bay-Richter, C., Linderholm, K. R., Lim, C. K., Samuelsson, M., Träskman-Bendz, L., Guillemin, G. J., et al. (2015). A role for inflammatory metabolites as modulators of the glutamate $\mathrm{N}$-methyl-d-aspartate receptor in depression and suicidality. Brain Behav. Immun. 43, 110-117. doi: 10.1016/J.BBI.2014.07.012

Beal, M. F., Matson, W. R., Swartz, K. J., Gamache, P. H., and Bird, E. D. (1990). Kynurenine pathway measurements in Huntington's disease striatum: evidence for reduced formation of Kynurenic Acid. J. Neurochem. 55, 1327-1339. doi: 10.1111/j.1471-4159.1990.tb03143.x

Behan, W. M. H., and Stone, T. W. (2000). Role of kynurenines in the neurotoxic actions of kainic acid. Br. J. Pharmacol. 129, 1764-1770. doi: 10.1038/sj.bjp. 0703250

Beninger, R. J., Colton, A. M., Ingles, J. L., Jhamandas, K., and Boegman, R. J. (1994). Picolinic acid blocks the neurotoxic but not the neuroexcitant properties of quinolinic acid in the rat brain: evidence from turning behaviour and tyrosine hydroxylase immunohistochemistry. Neuroscience 61, 603-612. doi: 10.1016/ 0306-4522(94)90438-3

Bizzarri, M., Catizone, A., Pompei, M., Chiappini, L., Curini, L., and Lagana, A. (1990). Determination of urinary tryptophan and its metabolites along the nicotinic acid pathway by high performance liquid chromatography with ultraviolet detection. Biomed. Chromatogr. 4, 24-27. doi: 10.1002/bmc. 1130040104

Bohár, Z., Toldi, J., Fülöp, F., Vécsei, L., Bohár, Z., Toldi, J., et al. (2015). Changing the face of Kynurenines and neurotoxicity: therapeutic considerations. Int. J. Mol. Sci. 16, 9772-9793. doi: 10.3390/ijms16059772

Brooks, B. R., Miller, R. G., Swash, M., and Munsat, T. L. (2000). El Escorial revisited: revised criteria for the diagnosis of amyotrophic lateral sclerosis. Amyotroph. Lateral Scler. 1, 293-299. doi: 10.1080/146608200300079536

Brundin, L., Sellgren, C. M., Lim, C. K., Grit, J., Pålsson, E., Landén, M., et al. (2016). An enzyme in the kynurenine pathway that governs vulnerability to suicidal behavior by regulating excitotoxicity and neuroinflammation. Transl. Psychiatry 6:e865. doi: 10.1038/tp.2016.133

Bryn, V., Verkerk, R., Skjeldal, O. H., Saugstad, O. D., and Ormstad, H. (2017). Kynurenine pathway in autism spectrum disorders in children. Neuropsychobiology 76, 82-88. doi: 10.1159/000488157

Byrne, L. M., and Wild, E. J. (2016). Cerebrospinal fluid biomarkers for Huntington's disease. J. Huntingtons Dis. 5, 1-13. doi: 10.3233/JHD- 160196

Camandola, S., and Mattson, M. P. (2017). Brain metabolism in health, aging, and neurodegeneration. EMBO J. 36, 1474-1492. doi: 10.15252/embj.201695810

Chatterjee, P., Goozee, K., Lim, C. K., James, I., Shen, K., Jacobs, K. R., et al. (2018). Alterations in serum kynurenine pathway metabolites in individuals with high neocortical amyloid- $\beta$ load: a pilot study. Sci. Rep. 8:8008. doi: 10.1038/s41598018-25968-7

Chen, Y., Stankovic, R., Cullen, K. M., Meininger, V., Garner, B., Coggan, S., et al. (2010). The Kynurenine pathway and inflammation in amyotropic lateral sclerosis. Neurotox. Res. 18, 132-142. doi: 10.1007/s12640-009-9129-7

Chiò, A., Mora, G., Calvo, A., Mazzini, L., Bottacchi, E., and Mutani, R. (2009). Epidemiology of ALS in Italy: a 10-year prospective population-based study. Neurology 72, 725-731. doi: 10.1212/01.wnl.0000343008.26874.d1
Choi, H. J., Kim, S. W., Lee, S. Y., and Hwang, O. (2004). Dopaminedependent cytotoxicity of tetrahydrobiopterin: a possible mechanism for selective neurodegeneration in Parkinson's disease. J. Neurochem. 86, 143-152. doi: $10.1046 / j .1471-4159.2003 .01808 . x$

Chuang, S.-C., Fanidi, A., Magne Ueland, P., Relton, C., Midttun, O., Vollset, S. E., et al. (2014). Circulating biomarkers of tryptophan and the Kynurenine pathway and lung cancer risk. Cancer Epidemiol Biomarkers Prev. 23, 461-468. doi: 10.1158/1055-9965.EPI-13-0770

Clarke, G., McKernan, D. P., Gaszner, G., Quigley, E. M., Cryan, J. F., and Dinan, T. G. (2012). A distinct profile of tryptophan metabolism along the Kynurenine pathway downstream of toll-like receptor activation in irritable Bowel Syndrome. Front. Pharmacol. 3:90. doi: 10.3389/fphar.2012.00090

Colín-González, A. L., Maldonado, P. D., and Santamaría, A. (2013). 3Hydroxykynurenine: an intriguing molecule exerting dual actions in the central nervous system. Neurotoxicology 34, 189-204. doi: 10.1016/j.neuro.2012.11.007

Colín-González, A. L., Paz-Loyola, A. L., Serratos, I., Seminotti, B., Ribeiro, C. A. J., Leipnitz, G., et al. (2015). Toxic synergism between quinolinic acid and organic acids accumulating in glutaric acidemia type I and in disorders of propionate metabolism in rat brain synaptosomes: relevance for metabolic acidemias. Neuroscience 308, 64-74. doi: 10.1016/J.NEUROSCIENCE.2015.09.002

Comai, S., Bertazzo, A., Vachon, J., Daigle, M., Toupin, J., Côté, G., et al. (2016). Tryptophan via serotonin/kynurenine pathways abnormalities in a large cohort of aggressive inmates: markers for aggression. Prog. Neuropsychopharmacol. Biol. Psychiatry 70, 8-16. doi: 10.1016/j.pnpbp.2016.04.012

Cronin, S. J. F., Seehus, C., Weidinger, A., Talbot, S., Reissig, S., Seifert, M., et al. (2018). The metabolite BH4 controls T cell proliferation in autoimmunity and cancer. Nature 563, 564-568. doi: 10.1038/s41586-018-0701-2

Curzon, G. (1979). "Relationships between plasma, CSF and brain tryptophan," in Transport Mechanisms of Tryptophan in Blood Cells, Nerve Cells, and at the Blood-Brain Barrier, ed. P. Baumann (Vienna: Springer), 81-92. doi: 10.1007/ 978-3-7091-2243-3_7

Darlington, L. G., Forrest, C. M., Mackay, G. M., Smith, R. A., Smith, A. J., Stoy, N., et al. (2010). On the biological importance of the 3-hydroxyanthranilic acid: anthranilic acid ratio. Int. J. Tryptophan Res. 3, 51-59. doi: 10.4137/IJTR.S4282

Darlington, L. G., Mackay, G. M., Forrest, C. M., Stoy, N., George, C., and Stone, T. W. (2007). Altered kynurenine metabolism correlates with infarct volume in stroke. Eur. J. Neurosci. 26, 2211-2221. doi: 10.1111/j.1460-9568.2007.05838.x

de Bie, J., Lim, C. K., and Guillemin, G. J. (2016a). Kynurenines, gender and neuroinflammation; showcase Schizophrenia. Neurotox. Res. 30, 285-294. doi: 10.1007/s12640-016-9641-5

de Bie, J., Lim, C. K., and Guillemin, G. J. (2016b). Progesterone alters kynurenine pathway activation in IFN- $\gamma$-activated macrophages - relevance for neuroinflammatory diseases. Int. J. Tryptophan Res. 9, 89-93. doi: 10.4137/IJTR. S40332

de Jong, W. H. A., Smit, R., Bakker, S. J. L., de Vries, E. G. E., and Kema, I. P. (2009). Plasma tryptophan, kynurenine and 3-hydroxykynurenine measurement using automated on-line solid-phase extraction HPLC-tandem mass spectrometry. J. Chromatogr. B 877, 603-609. doi: 10.1016/j.jchromb.2009.01.015

Dolina, S., Margalit, D., Malitsky, S., and Rabinkov, A. (2014). Attention-deficit hyperactivity disorder (ADHD) as a pyridoxine-dependent condition: urinary diagnostic biomarkers. Med. Hypotheses 82, 111-116. doi: 10.1016/J.MEHY. 2013.11.018

Dupuis, L., Oudart, H., René, F., Gonzalez de Aguilar, J.-L., and Loeffler, J.P. (2004). Evidence for defective energy homeostasis in amyotrophic lateral sclerosis: benefit of a high-energy diet in a transgenic mouse model. Proc. Natl. Acad. Sci. U.S.A. 101, 11159-11164. doi: 10.1073/pnas.0402026101

Erhardt, S., Lim, C. K., Linderholm, K. R., Janelidze, S., Lindqvist, D., Samuelsson, M., et al. (2013). Connecting inflammation with glutamate agonism in suicidality. Neuropsychopharmacology 38, 743-752. doi: 10.1038/npp. 2012.248

Favre, D., Mold, J., Hunt, P. W., Kanwar, B., Loke, P., Seu, L., et al. (2010). Tryptophan catabolism by indoleamine 2,3-dioxygenase 1 alters the balance of TH17 to regulatory T cells in HIV disease. Sci. Transl. Med. 2:32ra36. doi: 10.1126/scitranslmed.3000632

Feng, S., Du, Y.-Q., Zhang, L. L., Zhang, L. L., Feng, R.-R., and Liu, S.Y. (2015). Analysis of serum metabolic profile by ultra-performance liquid chromatography-mass spectrometry for biomarkers discovery: application in 
a pilot study to discriminate patients with tuberculosis. Chin. Med. J. 128, 159-168. doi: 10.4103/0366-6999.149188

Finger, E., Wong, J., Gray, J., Rock, D., Loberg, R., Fitzpatrick, D., et al. (2017). Utilization of metabolomics to identify biomarkers in hematological malignancies: role of IDO and the Tryptophan pathway. Blood 130:5100.

Foster, A. C., Vezzani, I., and French, E. D. (1984). Kynurenic acid blocks neurotoxicity and seizures induc- Ed in rats by the related brain metabolite quinolinic acid. Neurosci. Lett. 48, 273-278. doi: 10.1016/0304-3940(84) 90050-8

Foxton, R. H., Land, J. M., and Heales, S. J. R. (2007). Tetrahydrobiopterin availability in Parkinson's and Alzheimer's disease; potential pathogenic mechanisms. Neurochem. Res. 32, 751-756. doi: 10.1007/s11064-006-9201-0

Fuchs, D., Forsman, A., Hagberg, L., Larsson, M., Norkrans, G., Reibnegger, G., et al. (1990). Immune activation and decreased tryptophan in patients with HIV-1 infection. J. Interferon Res. 10, 599-603. doi: 10.1089/jir.1990. 10.599

Fukui, S., Schwarcz, R., Rapoport, S. I., Takada, Y., and Smith, Q. R. (1991). Blood? brain barrier transport of Kynurenines: implications for brain synthesis and metabolism. J. Neurochem. 56, 2007-2017. doi: 10.1111/j.1471-4159.1991. tb03460.x

Fukuwatari, T., Wada, H., Sasaki, R., and Shibata, K. (2004). Effects of excess nicotinamide administration on the urinary excretion of nicotinamide $\mathrm{N}$ Oxide and nicotinuric acid by rats. Biosci. Biotechnol. Biochem. 68, 44-50. doi: 10.1271/bbb.68.44

Füvesi, J., Rajda, C., Bencsik, K., Toldi, J., and Vécsei, L. (2012). The role of kynurenines in the pathomechanism of amyotrophic lateral sclerosis and multiple sclerosis: therapeutic implications. J. Neural Transm. 119, 225-234. doi: $10.1007 / \mathrm{s} 00702-012-0765-3$

Gabbay, V., Klein, R. G., Katz, Y., Mendoza, S., Guttman, L. E., Alonso, C. M., et al. (2010). The possible role of the kynurenine pathway in adolescent depression with melancholic features. J. Child Psychol. Psychiatry 51, 935-943. doi: 10.1111/ j.1469-7610.2010.02245.x

Ganesalingam, J., and Bowser, R. (2010). The application of biomarkers in clinical trials for motor neuron disease. Biomark. Med. 4, 281-297. doi: 10.2217/bmm. 09.71

Ghisoni, K., Martins Rde, P., Barbeito, L., and Latini, A. (2015). Neopterin as a potential cytoprotective brain molecule. J. Psychiatr. Res. 71, 134-139. doi: 10.1016/j.jpsychires.2015.10.003

Gil, J., Preux, P., Alioum, A., Ketzoian, C., Desport, J., Druet-cabanac, M., et al. (2017). Disease progression and survival in ALS: first multi-state model approach Disease progression and survival in ALS: first multistate model approach. Amyotroph. Lateral Scler. 8, 224-229. doi: 10.1080/ 17482960701278562

Giusti, R. M., Maloney, E. M., Hanchard, B., Morgan, O. S., Steinberg, S. M., Wachter, H., et al. (1996). Differential patterns of serum biomarkers of immune activation in human T-cell lymphotropic virus type I-associated myelopathy/tropical spastic paraparesis, and adult T-cell leukemia/lymphoma. Cancer Epidemiol. Biomark. Prev. 5, 699-704.

Gostner, J. M., Geisler, S., Becker, K., Fuchs, D., Mayersbach, P., Schennach, H., et al. (2015). Serum tryptophan, kynurenine, phenylalanine, tyrosine and neopterin concentrations in 100 healthy blood donors. Pteridines 26, 31-36. doi: 10.1515/pterid-2014-0015

Grant, R., Nguyen, S., and Guillemin, G. (2010). Kynurenine pathway metabolism is involved in the maintenance of the intracellular NAD concentration in human primary astrocytes. Int. J. Tryptophan Res. 3, 151-156.

Grant, R. S., Coggan, S. E., and Smythe, G. A. (2009). The physiological action of picolinic acid in the human brain. Int. J. Tryptophan Res. 2, 71-79.

Guidetti, P., and Schwarcz, R. (1999). 3-Hydroxykynurenine potentiates quinolinate but not NMDA toxicity in the rat striatum. Eur. J. Neurosci. 11, 3857-3863. doi: 10.1046/j.1460-9568.1999.00806.x

Guillemin, G. J. (2012a). Quinolinic acid, the inescapable neurotoxin. FEBS J. 279, 1356-1365. doi: 10.1111/j.1742-4658.2012.08485.x

Guillemin, G. J. (2012b). Quinolinic acid: neurotoxicity. FEBS J. 279:1355. doi: $10.1111 / j .1742-4658.2012 .08493 . x$

Guillemin, G. J., Brew, B. J., Noonan, C. E., Takikawa, O., and Cullen, K. M. (2005a). Indoleamine 2,3 dioxygenase and quinolinic acid immunoreactivity in Alzheimer's disease hippocampus. Neuropathol. Appl. Neurobiol. 31, 395-404. doi: $10.1111 / j .1365-2990.2005 .00655 . x$
Guillemin, G. J., Kerr, S. J., and Brew, B. J. (2005b). Involvement of quinolinic acid in AIDS dementia complex. Neurotox. Res. 7, 103-123. doi: 10.1007/ bf03033781

Guillemin, G. J., Smythe, G., Takikawa, O., and Brew, B. J. (2005c). Expression of indoleamine 2,3-dioxygenase and production of quinolinic acid by human microglia, astrocytes, and neurons. Glia 49, 15-23. doi: 10.1002/glia.20090

Guillemin, G. J., Croitoru-Lamoury, J., Dormont, D., Armati, P. J., and Brew, B. J. (2003a). Quinolinic acid upregulates chemokine production and chemokine receptor expression in astrocytes. Glia 41, 371-381. doi: 10.1002/glia.10175

Guillemin, G. J., Smith, D. G., Smythe, G. A., Armati, P. J., and Brew, B. J. (2003b). Expression of the kynurenine pathway enzymes in human microglia and macrophages. Adv. Exp. Med. Biol. 527, 105-112. doi: 10.1007/978-1-46150135-0_12

Guillemin, G. J., Cullen, K. M., Lim, C. K., Smythe, G. A., Garner, B., Kapoor, V., et al. (2007). Characterization of the kynurenine pathway in human neurons. J. Neurosci. 27, 12884-12892. doi: 10.1523/JNEUROSCI.4101-07.2007

Guillemin, G. J., Kerr, S. J., Smythe, G. A., Smith, D. G., Kapoor, V., Armati, P. J., et al. (2001). Kynurenine pathway metabolism in human astrocytes: a paradox for neuronal protection. J. Neurochem. 78, 842-853. doi: 10.1046/j.1471-4159. 2001.00498.x

Guillemin, G. J. J., Smith, D. G. G., Kerr, S. J. J., Smythe, G. A. A., Kapoor, V., Armati, P. J. J., et al. (2000). Characterisation of kynurenine pathway metabolism in human astrocytes and implications in neuropathogenesis. Redox Rep. 5, 108-111. doi: 10.1179/135100000101535375

Guix, F. X., Uribesalgo, I., Coma, M., and Muñoz, F. J. (2005). The physiology and pathophysiology of nitric oxide in the brain. Prog. Neurobiol. 76, 126-152. doi: 10.1016/j.pneurobio.2005.06.001

Gupta, N. K., Thaker, A. I., Kanuri, N., Riehl, T. E., Rowley, C. W., Stenson, W. F., et al. (2012). Serum analysis of tryptophan catabolism pathway: correlation with Crohn's disease activity. Inflamm. Bowel Dis. 18, 1214-1220. doi: 10.1002/ibd. 21849

Hardiman, O., Al-Chalabi, A., Chio, A., Corr, E. M., Logroscino, G., Robberecht, W., et al. (2017). Amyotrophic lateral sclerosis. Nat. Rev. Dis. Prim. 3:17071.

Hartai, Z., Juhász, A., Rimanóczy, Á, Janáky, T., Donkó, T., Dux, L., et al. (2007). Decreased serum and red blood cell kynurenic acid levels in Alzheimer's disease. Neurochem. Int. 50, 308-313. doi: 10.1016/j.neuint.2006.08.012

Havelund, J. F., Andersen, A. D., Binzer, M., Blaabjerg, M., Heegaard, N. H. H., Stenager, E., et al. (2017). Changes in kynurenine pathway metabolism in Parkinson patients with L-DOPA-induced dyskinesia. J. Neurochem. 142, 756-766. doi: 10.1111/jnc.14104

Heyes, M. P., Brew, B., Martin, A., Markey, S. P., Price, R. W., Bhalla, R. B., et al. (1991). Cerebrospinal fluid quinolinic acid concentrations are increased in acquired immune deficiency syndrome. Adv. Exp. Med. Biol. 294, 687-690. doi: 10.1007/978-1-4684-5952-4_94

Heyes, M. P., Brew, B. J., Saito, K., Quearry, B. J., Price, R. W., Lee, K., et al. (1992). Inter-relationships between quinolinic acid, neuroactive kynurenines, neopterin and $\beta 2$-microglobulin in cerebrospinal fluid and serum of HIV1-infected patients. J. Neuroimmunol. 40, 71-80. doi: 10.1016/0165-5728(92) 90214-6

Heyes, M. P., Chen, C. Y., Major, E. O., and Saito, K. (1997). Different kynurenine pathway enzymes limit quinolinic acid formation by various human cell types. Biochem. J. 326(Pt 2), 351-356. doi: 10.1042/bj3260351

Heyes, M. P., Hutto, B., and Markey, S. P. (1988). 4-chloro-3-hydroxyanthranilate inhibits brain 3-hydroxyanthranate oxidase. Neurochem. Int. 13, 405-408. doi: 10.1016/0197-0186(88)90015-0

Heyes, M. P., and Markey, S. P. (1988). Quantification of quinolinic acid in rat brain, whole blood, and plasma by gas chromatography and negative chemical ionization mass spectrometry: effects of systemic l-tryptophan administration on brain and blood quinolinic acid concentrations. Anal. Biochem. 174, 349359. doi: 10.1016/0003-2697(88)90556-8

Hirayama, A., Nakashima, E., Sugimoto, M., Akiyama, S., Sato, W., Maruyama, S., et al. (2012). Metabolic profiling reveals new serum biomarkers for differentiating diabetic nephropathy. Anal. Bioanal. Chem. 404, 3101-3109. doi: $10.1007 / \mathrm{s} 00216-012-6412-\mathrm{x}$

Huang, J. Y., Butler, L. M., Midttun, Ø., Ulvik, A., Wang, R., Jin, A., et al. (2018). A prospective evaluation of serum kynurenine metabolites and risk of pancreatic cancer. PLoS One 13:e0196465. doi: 10.1371/journal.pone.019 6465 
Ilzecka, J., Kocki, T., Stelmasiak, Z., and Turski, W. A. (2003). Endogenous protectant kynurenic acid in amyotrophic lateral sclerosis. Acta Neurol. Scand. 107, 412-418. doi: 10.1034/j.1600-0404.2003.00076.x

Imai, S., and Yoshino, J. (2013). The importance of NAMPT/NAD/SIRT1 in the systemic regulation of metabolism and ageing. Diabetes Obes. Metab. 15, 26-33. doi: $10.1111 /$ dom.12171

Jacobs, K. R., Lim, C. K., Blennow, K., Zetterberg, H., Chatterjee, P., Martins, R. N., et al. (2019). Correlation between plasma and CSF concentrations of kynurenine pathway metabolites in Alzheimer's disease and relationship to amyloid- $\beta$ and tau. Neurobiol. Aging 80, 11-20. doi: 10.1016/j.neurobiolaging. 2019.03.015

Jacobs, K. R., and Lovejoy, D. B. (2018). Inhibiting the kynurenine pathway in spinal cord injury: multiple therapeutic potentials? Neural Regen. Res. 13, 2073-2076. doi: 10.4103/1673-5374.241446

Jhamandas, K., Boegman, R. J. J., Beninger, R. J. J., and Bialik, M. (1990). Quinolinate-induced cortical cholinergic damage: modulation by tryptophan metabolites. Brain Res. 529, 185-191. doi: 10.1016/0006-8993(90)90826-W

Jin, H., Zhang, Y., You, H., Tao, X., Wang, C., Jin, G., et al. (2015). Prognostic significance of kynurenine 3-monooxygenase and effects on proliferation, migration and invasion of human hepatocellular carcinoma. Sci. Rep. 5:10466. doi: $10.1038 /$ srep 10466

Jones, S. P., Franco, N. F., Varney, B., Sundaram, G., Brown, D. A., de Bie, J., et al. (2015). Expression of the Kynurenine pathway in human peripheral blood mononuclear cells: implications for inflammatory and neurodegenerative disease. PLoS One 10:e0131389. doi: 10.1371/journal.pone.0131389

Kalonia, H., Kumar, P., and Kumar, A. (2011). Attenuation of proinflammatory cytokines and apoptotic process by verapamil and diltiazem against quinolinic acid induced Huntington like alterations in rats. Brain Res. 1372, 115-126. doi: 10.1016/j.brainres.2010.11.060

Kalonia, H., Mishra, J., and Kumar, A. (2012). Targeting neuro-inflammatory cytokines and oxidative stress by minocycline attenuates quinolinic-acidinduced Huntington's disease-like symptoms in rats. Neurotox. Res. 22, 310-320. doi: 10.1007/s12640-012-9315-x

Kegel, M. E., Bhat, M., Skogh, E., Samuelsson, M., Lundberg, K., Dahl, M.-L., et al. (2014). Imbalanced kynurenine pathway in schizophrenia. Int. J. Tryptophan Res. 7, 15-22. doi: 10.4137/IJTR.S16800

Khan, A., Choi, S. A., Na, J., Pamungkas, A. D., Jung, K. J., Jee, S. H., et al. (2019). Noninvasive serum metabolomic profiling reveals elevated Kynurenine pathway's metabolites in humans with prostate cancer. J. Proteome Res. 18, 1532-1541. doi: 10.1021/acs.jproteome.8b00803

Khaspekov, L., Kida, E., Victorov, I., and Mossakowski, M. J. (1989). Neurotoxic effect induced by quinolinic acid in dissociated cell culture of mouse hippocampus. J. Neurosci. Res. 22, 150-157. doi: 10.1002/jnr.4902 20207

Kim, J. P., and Choi, D. W. (1987). Quinolinate neurotoxicity in cortical cell culture. Neuroscience 23, 423-432. doi: 10.1016/0306-4522(87)90066-2

Kocki, T., Wnuk, S., Kloc, R., Kocki, J., Owe-Larsson, B., and Urbanska, E. M. (2012). New insight into the antidepressants action: modulation of kynurenine pathway by increasing the kynurenic acid/3-hydroxykynurenine ratio. J. Neural Transm. 119, 235-243. doi: 10.1007/s00702-011-0668-8

Koh, J. Y., and Choi, D. W. (1988). Vulnerability of cultured cortical neurons to damage by excitotoxins: differential susceptibility of neurons containing NADPH-diaphorase. J. Neurosci. 8, 2153-2163. doi: 10.1523/jneurosci.08-0602153.1988

Kosek, M. N., Mduma, E., Kosek, P. S., Lee, G. O., Svensen, E., Pan, W. K. Y., et al. (2016). Plasma tryptophan and the Kynurenine-tryptophan ratio are associated with the acquisition of statural growth deficits and oral vaccine underperformance in populations with environmental enteropathy. Am. J. Trop. Med. Hyg. 95, 928-937. doi: 10.4269/ajtmh.16-0037

Krause, D., Suh, H.-S., Tarassishin, L., Cui, Q. L., Durafourt, B. A., Choi, N., et al. (2011). The tryptophan metabolite 3-hydroxyanthranilic acid plays antiinflammatory and neuroprotective roles during inflammation. Am. J. Pathol. 179, 1360-1372. doi: 10.1016/j.ajpath.2011.05.048

Küster, O. C., Laptinskaya, D., Fissler, P., Schnack, C., Zügel, M., Nold, V., et al. (2017). Novel blood-based biomarkers of cognition, stress, and physical or cognitive training in older adults at risk of Dementia: preliminary evidence for a role of BDNF, Irisin, and the Kynurenine pathway. J. Alzheimer's Dis. 59, 1097-1111. doi: 10.3233/JAD- 170447
Kuwano, N., Kato, T. A., Setoyama, D., Sato-Kasai, M., Shimokawa, N., Hayakawa, K., et al. (2018). Tryptophan-kynurenine and lipid related metabolites as blood biomarkers for first-episode drug-naive patients with major depressive disorder: an exploratory pilot case-control study. J. Affect. Disord. 231, 74-82. doi: 10.1016/J.JAD.2018.01.014

Lambrechts, D., Robberecht, W., and Carmeliet, P. (2007). Heterogeneity in motoneuron disease. Trends Neurosci. 30, 536-544. doi: 10.1016/j.tins.2007. 07.002

Lee, J.-M. M., Tan, V., Lovejoy, D., Braidy, N., Rowe, D. B., Brew, B. J., et al. (2017). Involvement of quinolinic acid in the neuropathogenesis of amyotrophic lateral sclerosis. Neuropharmacology 112, 346-364. doi: 10.1016/j.neuropharm.2016. 05.011

Lee, S. A., Mefford, J. A., Huang, Y., Witte, J. S., Martin, J. N., Haas, D. W., et al. (2016). Host genetic predictors of the kynurenine pathway of tryptophan catabolism among treated HIV-infected Ugandans. AIDS 30, 1807-1815. doi: 10.1097/QAD.0000000000001124

Leipnitz, G., Schumacher, C., Dalcin, K. B., Scussiato, K., Solano, A., Funchal, C., et al. (2007). In vitro evidence for an antioxidant role of 3-hydroxykynurenine and 3-hydroxyanthranilic acid in the brain. Neurochem. Int. 50, 83-94. doi: 10.1016/j.neuint.2006.04.017

Lepage, N., Mcdonald, N., Dallaire, L., and Lambert, M. (1997). Diet-related reference values for plasma amino acids in newborns measured by reversedphase HPLC. Clin. Chem. 43, 2397-2402.

Lewitt, P. A., Li, J., Lu, M., Beach, T. G., Adler, C. H., and Guo, L. (2013). 3hydroxykynurenine and other Parkinson's disease biomarkers discovered by metabolomic analysis. Mov. Disord. 28, 1653-1660. doi: 10.1002/mds.25555

Lim, C. K., Bilgin, A., Lovejoy, D. B., Tan, V., Bustamante, S., Taylor, B. V., et al. (2017). Kynurenine pathway metabolomics predicts and provides mechanistic insight into multiple sclerosis progression. Sci. Rep. 7:41473. doi: 10.1038/ srep41473

Lim, C. K., Smythe, G. A., Stocker, R., Brew, B. J., and Guillemin, G. J. (2007). Characterization of the kynurenine pathway in human oligodendrocytes. Int. Congr. Ser. 1304, 213-217. doi: 10.1016/J.ICS.2007.07.011

Lim, C. K., Yap, M. M. C., Kent, S. J., Gras, G., Samah, B., Batten, J. C., et al. (2013). Characterization of the kynurenine pathway and quinolinic Acid production in macaque macrophages. Int. J. Tryptophan Res. 6, 7-19. doi: 10.4137/IJTR. S11789

Liu, H., Ding, L., Zhang, H., Mellor, D., Wu, H., Zhao, D., et al. (2018). The metabolic factor Kynurenic acid of Kynurenine pathway predicts major depressive disorder. Front. Psychiatry 9:552. doi: 10.3389/fpsyt.2018.00552

Lugo-Huitrón, R., Blanco-Ayala, T., Ugalde-Muñiz, P., Carrillo-Mora, P., PedrazaChaverrí, J., Silva-Adaya, D., et al. (2011). On the antioxidant properties of kynurenic acid: free radical scavenging activity and inhibition of oxidative stress. Neurotoxicol. Teratol. 33, 538-547. doi: 10.1016/J.NTT.2011.07.002

Mackay, G. M., Forrest, C. M., Christofides, J., Bridel, M. A., Mitchell, S., Cowlard, R., et al. (2009). Kynurenine metabolites and inflammation markers in depressed patients treated with fluoxetine or counselling. Clin. Exp. Pharmacol. Physiol. 36, 425-435. doi: 10.1111/j.1440-1681.2008.05077.x

Maes, M., Leonard, B. E., Myint, A. M., Kubera, M., and Verkerk, R. (2011). The new "5-HT" hypothesis of depression: cell-mediated immune activation induces indoleamine 2,3-dioxygenase, which leads to lower plasma tryptophan and an increased synthesis of detrimental tryptophan catabolites (TRYCATs), both of which contribute to th. Prog. Neuro Psychopharmacol. Biol. Psychiatry 35, 702-721. doi: 10.1016/j.pnpbp.2010.12.017

Mangge, H., Summers, K. L., Meinitzer, A., Zelzer, S., Almer, G., Prassl, R., et al. (2014). Obesity-related dysregulation of the Tryptophan-Kynurenine metabolism: role of age and parameters of the metabolic syndrome. Obesity 22, 195-201. doi: 10.1002/oby.20491

Mawatari, K., Oshida, K., Iinuma, F., and Watanabe, M. (1995). Determination of quinolinic acid in human urine by liquid chromatography with fluorimetric detection. Anal. Chim. Acta 302, 179-183. doi: 10.1016/0003-2670(94)00493-6

McGeer, P. L., and McGeer, E. G. (2002). Inflammatory processes in amyotrophic lateral sclerosis. Muscle Nerve 26, 459-470. doi: 10.1002/mus.10191

McManus, I. R., and Jackson, M. (1968). Isolation and assay of radioactive urinary kynurenic and xanthurenic acids. Anal. Biochem. 23, 163-172. doi: 10.1016/ 0003-2697(68)90022-5

McMillan, M. (1960). The identification of a fluorescent reducing substance in the urine of patients with rheumatoid arthritis: the excretion of 
3-hydroxyanthranilic acid in this and other conditions. J. Clin. Pathol. 13, 140-148. doi: 10.1136/JCP.13.2.140

Medana, I. M., Day, N. P. J., Salahifar-Sabet, H., Stocker, R., Smythe, G., Bwanaisa, L., et al. (2003). Metabolites of the Kynurenine pathway of tryptophan metabolism in the cerebrospinal fluid of Malawian Children with Malaria. J. Infect. Dis. 188, 844-849. doi: 10.1086/377583

Midttun, $\varnothing$, Townsend, M. K., Nygård, O., Tworoger, S. S., Brennan, P., Johansson, M., et al. (2014). Most blood biomarkers related to vitamin status, onecarbon metabolism, and the Kynurenine pathway show adequate preanalytical stability and within-person reproducibility to allow assessment of exposure or nutritional status in healthy women and cardiovascular patients. J. Nutr. 144, 784-790. doi: 10.3945/jn.113.189738

Miller, D., Tan, L., Dorshorst, D., Morrissey, K., Mahrus, S., Milanowski, D., et al. (2018). A validated surrogate analyte LC-MS/MS assay for quantitation of endogenous kynurenine and tryptophan in human plasma. Bioanalysis 10, 1307-1317. doi: 10.4155/bio-2018-0044

Moffett, J. R., and Namboodiri, M. A. (2003). Tryptophan and the immune response. Immunol. Cell Biol. 81, 247-265. doi: 10.1046/j.1440-1711.2003.t011-01177.x

Müller, N., and Schwarz, M. (2006). Schizophrenia as an inflammation-mediated dysbalance of glutamatergic neurotransmission. Neurotox. Res. 10, 131-148. doi: 10.1007/BF03033242

Musajo, L., Benassi, C. A., and Parpajola, A. (1955). Isolation of Kynurenine and 3-Hydroxykynurenine from human pathological urine. Nature 175, 855-856. doi: $10.1038 / 175855 \mathrm{a} 0$

Musajo, L., Benassi, C. A., and Parpajola, A. (1956). Excretion and isolation of kynurenine and 3-hydroxykynurenine from human pathological urine. Clin. Chim. Acta 1, 229-235. doi: 10.1016/0009-8981(56)90069-9

Myint, A. M. (2012). Kynurenines: from the perspective of major psychiatric disorders. FEBS J. 279, 1375-1385. doi: 10.1111/j.1742-4658.2012.08551.x

Nakagami, Y., Saito, H., and Katsuki, H. (1996). 3-Hydroxykynurenine toxicity on the rat striatum in vivo. Jpn. J. Pharmacol. 71, 183-186. doi: 10.1254/jjp.71.183

Ngo, S. T., and Steyn, F. J. (2015). The interplay between metabolic homeostasis and neurodegeneration: insights into the neurometabolic nature of amyotrophic lateral sclerosis. Cell Regen. 4:5. doi: 10.1186/s13619-015-0019-6

Nilsen, R. M., Bjørke-Monsen, A.-L., Midttun, O., Nygård, O., Pedersen, E. R., Ulvik, A., et al. (2012). Maternal tryptophan and kynurenine pathway metabolites and risk of preeclampsia. Obstet. Gynecol. 119, 1243-1250. doi: 10.1097/AOG.0b013e318255004e

Ogawa, T., Matson, W. R., Beal, M. F., Myers, R. H., Bird, E. D., Milbury, P., et al. (1992). Kynurenine pathway abnormalities in Parkinson's disease. Neurology 42, 1702-1706. doi: 10.1212/WNL.42.9.1702

Olsson, S. K., Samuelsson, M., Saetre, P., Lindström, L., Jönsson, E. G., Nordin, C., et al. (2010). Elevated levels of kynurenic acid in the cerebrospinal fluid of patients with bipolar disorder. J. Psychiatry Neurosci. 35, 195-199. doi: 10.1503/ jpn.090180

Owens, M. J., and Nemeroff, C. B. (1994). Role of serotoninin the pathophysiology of depression:focus on the serotonintransporter. Clin. Chem. 40, 288-295.

Owe-Young, R., Webster, N. L., Mukhtar, M., Pomerantz, R. J., Smythe, G., Walker, D., et al. (2008). Kynurenine pathway metabolism in human bloodbrain-barrier cells: implications for immune tolerance and neurotoxicity. J. Neurochem. 105, 1346-1357. doi: 10.1111/j.1471-4159.2008.05241.x

Oxenkrug, G. (2013). Insulin resistance and dysregulation of tryptophankynurenine and kynurenine-nicotinamide adenine dinucleotide metabolic pathways. Mol. Neurobiol. 48, 294-301. doi: 10.1007/s12035-013-8497-4

Oxenkrug, G., van der Hart, M., Roeser, J., and Summergrad, P. (2016). Anthranilic acid: a potential biomarker and treatment target for Schizophrenia. Ann. psychiatry Ment. Heal. 4:1059.

Oxenkrug, G. F. (2007). Genetic and hormonal regulation of TryptophanKynurenine metabolism. Ann. N. Y. Acad. Sci. 1122, 35-49. doi: 10.1196/annals. 1403.003

Oxenkrug, G. F. (2011). Interferon-gamma-inducible kynurenines/pteridines inflammation cascade: implications for aging and aging-associated psychiatric and medical disorders NIH public access. J. Neural Transm. 118, 75-85. doi: $10.1007 /$ s00702-010-0475-7

Park, W. G., Wu, M., Bowen, R., Zheng, M., Fitch, W. L., Pai, R. K., et al. (2013). Metabolomic-derived novel cyst fluid biomarkers for pancreatic cysts: glucose and kynurenine. Gastrointest. Endosc. 78, 295.e2-302.e2. doi: 10.1016/j.gie. 2013.02.037

Pedersen, E. R., Svingen, G. F. T., Schartum-Hansen, H., Ueland, P. M., Ebbing, M., Nordrehaug, J. E., et al. (2013). Urinary excretion of kynurenine and tryptophan, cardiovascular events, and mortality after elective coronary angiography. Eur. Heart J. 34, 2689-2696. doi: 10.1093/eurheartj/eht264

Pehar, M., Harlan, B. A., Killoy, K. M., and Vargas, M. R. (2018). Nicotinamide adenine dinucleotide metabolism and neurodegeneration. Antioxid. Redox Signal. 28, 1652-1668. doi: 10.1089/ars.2017.7145

Pérez-González, A., Raú Alvarez-Idaboy, J., and Galano, A. (2017). Dual antioxidant/pro-oxidant behavior of the tryptophan metabolite 3hydroxyanthranilic acid: a theoretical investigation of reaction mechanisms and kinetics. New J. Chem. 41, 3829-3845. doi: 10.1039/c6nj03980d

Perkins, M. N. N., and Stone, T. W. W. (1982). An iontophoretic investigation of the actions of convulsant kynurenines and their interaction with the endogenous excitant quinolinic acid. Brain Res. 247, 184-187. doi: 10.1016/ 0006-8993(82)91048-4

Perl, A. (2015). mTOR activation is a biomarker and a central pathway to autoimmune disorders, cancer, obesity, and aging. Ann. N. Y. Acad. Sci. 1346, 33-44. doi: 10.1111/nyas.12756

Petrov, D., Mansfield, C., Moussy, A., and Hermine, O. (2017). ALS clinical trials review: 20 years of failure. Are we any closer to registering a new treatment? Front. Aging Neurosci. 9:68. doi: 10.3389/fnagi.2017.00068

Pierozan, P., Ferreira, F., de Lima, B. O., and Pessoa-Pureur, R. (2015). Quinolinic acid induces disrupts cytoskeletal homeostasis in striatal neurons. Protective role of astrocyte-neuron interaction. J. Neurosci. Res. 93, 268-284. doi: 10.1002/ jnr.23494

Pierozan, P., Zamoner, A., Krombauer Soska, Â, Bristot Silvestrin, R., Oliveira Loureiro, S., Heimfarth, L., et al. (2010). Acute intrastriatal administration of quinolinic acid provokes hyperphosphorylation of cytoskeletal intermediate filament proteins in astrocytes and neurons of rats. Exp. Neurol. 224, 188-196. doi: 10.1016/j.expneurol.2010.03.009

Procaccini, C., Santopaolo, M., Faicchia, D., Colamatteo, A., Formisano, L., de Candia, P., et al. (2016). Role of metabolism in neurodegenerative disorders. Metabolism 65, 1376-1390. doi: 10.1016/J.METABOL.2016.05.018

Puccetti, P., Fallarino, F., Italiano, A., Soubeyran, I., MacGrogan, G., Debled, M., et al. (2015). Accumulation of an endogenous tryptophan-derived metabolite in colorectal and breast cancers. PLoS One 10:e0122046. doi: 10.1371/journal. pone. 0122046

Quagliariello, E., Papa, S., Saccone, C., and Alifano, A. (1964). Effect of 3Hydroxyanthranilic acid on the mitochondrial respiratory system. Biochem J. 91, 137-146. doi: 10.1042/bj0910137

Rejdak, K., Bartosik-Psujek, H., Dobosz, B., Kocki, T., Grieb, P., Giovannoni, G., et al. (2002). Decreased level of kynurenic acid in cerebrospinal fluid of relapsing-onset multiple sclerosis patients. Neurosci. Lett. 331, 63-65. doi: 10. 1016/S0304-3940(02)00710-3

Ribeiro, C. A. J., Grando, V., Dutra Filho, C. S., Wannmacher, C. M. D. and Wajner, M. (2006). Evidence that quinolinic acid severely impairs energy metabolism through activation of NMDA receptors in striatum from developing rats. J. Neurochem. 99, 1531-1542. doi: 10.1111/j.1471-4159.2006. 04199.x

Ruddick, J. P., Evans, A. K., Nutt, D. J., Lightman, S. L., Rook, G. A. W., and Lowry, C. A. (2006). Tryptophan metabolism in the central nervous system: medical implications. Expert Rev. Mol. Med. 8, 1-27. doi: 10.1017/s1462399406000068

Sakai, N., Kaufman, S., and Milstien, S. (1995). Parallel induction of nitric oxide and tetrahydrobiopterin synthesis by cytokines in rat glial cells. J. Neurochem. 65, 895-902. doi: 10.1046/j.1471-4159.1995.65020895.x

Sandyk, R. (2006). Serotonergic mechanisms in amyotrophic lateral sclerosis. Int. J. Neurosci. 116, 775-826. doi: 10.1080/00207450600754087

Sardar, A. M., Bell, J. E., and Reynolds, G. P. (2002). Increased concentrations of the Neurotoxin 3-Hydroxykynurenine in the frontal cortex of HIV-1-positive patients. J. Neurochem. 64, 932-935. doi: 10.1046/j.1471-4159.1995.64020932.x

Sasaki, Y. (2019). Metabolic aspects of neuronal degeneration: from a NAD+ point of view. Neurosci. Res. 139, 9-20. doi: 10.1016/j.neures.2018.07.001

Sasaki, Y., Araki, T., and Milbrandt, J. (2006). Stimulation of nicotinamide adenine dinucleotide biosynthetic pathways delays axonal degeneration after axotomy. J. Neurosci. 26, 8484-8491. doi: 10.1523/JNEUROSCI.2320-06.2006 
Sathyasaikumar, K. V., Stachowski, E. K., Wonodi, I., Roberts, R. C., Rassoulpour, A., McMahon, R. P., et al. (2011). Impaired kynurenine pathway metabolism in the prefrontal cortex of individuals with schizophrenia. Schizophr. Bull. 37, 1147-1156. doi: 10.1093/schbul/sbq112

Schroecksnadel, K., Kaser, S., Ledochowski, M., Neurauter, G., Mur, E., Herold, M., et al. (2003). Increased degradation of tryptophan in blood of patients with rheumatoid arthritis. J. Rheumatol. 30, 1935-1939.

Schwarcz, R., Okuno, E., White, R. J., Birdt, E. D., and Whetsell, W. O. (1988). 3-Hydroxyanthranilate oxygenase activity is increased in the brains of Huntington disease victims (kynurenines/quinolinic acid/excitotoins/neurodegenerative disorders). Neurobiology 85, 4079-4081. doi: $10.1073 /$ pnas.85.11.4079

Shibata, K. (1988). Fluorimetric micro-determination of kynurenic acid, an endogenous blocker of neurotoxicity, by high-performance liquid chromatography. J. Chromatogr. B Biomed. Sci. Appl. 430, 376-380. doi: 10. 1016/S0378-4347(00)83173-4

Shoki, O., Nobuyoshi, N., Hiroshi, S., Hiroshi, K., Okuda, S., Nishiyama, N., et al. (1998). 3-Hydroxykynurenine, an endogenous oxidative stress generator, causes neuronal cell death with apoptotic features and region selectivity. J. Neurochem. 70, 299-307. doi: 10.1046/j.1471-4159.1998.70010299.x

Smythe, G. A., Poljak, A., Bustamante, S., Braga, O., Maxwell, A., Grant, R., et al. (2003). ECNI GC-MS analysis of picolinic and quinolinic acids and their amides in human plasma, CSF, and brain tissue. Adv. Exp. Med. Biol. 527, 705-712. doi: 10.1007/978-1-4615-0135-0_83

Spiera, H., and Vallarino, R. (1969). Serum kynurenine in rheumatoid arthritis. J. Clin. Invest. 48, 856-859. doi: 10.1172/JCI106043

Steiner, J., Walter, M., Gos, T., Guillemin, G. J., Bernstein, H.-G., Sarnyai, Z., et al. (2011). Severe depression is associated with increased microglial quinolinic acid in subregions of the anterior cingulate gyrus: evidence for an immunemodulated glutamatergic neurotransmission? J. Neuroinflamm. 8:94. doi: 10. 1186/1742-2094-8-94

Stone, T. (1993). Neuropharmacology of quinolinic and kynurenic acids. Pharmacol. Rev. 45, 309-379.

Stone, T. W., Forrest, C. M., and Darlington, L. G. (2012). Kynurenine pathway inhibition as a therapeutic strategy for neuroprotection. FEBS J. 279, 1386-1397. doi: 10.1111/j.1742-4658.2012.08487.x

Stoy, N., Mackay, G. M., Forrest, C. M., Christofides, J., Egerton, M., Stone, T. W., et al. (2005). Tryptophan metabolism and oxidative stress in patients with Huntington's disease. J. Neurochem. 93, 611-623. doi: 10.1111/j.1471-4159. 2005.03070.x

Sühs, K.-W., Novoselova, N., Kuhn, M., Seegers, L., Kaever, V., Müller-Vahl, K., et al. (2019). Kynurenine is a cerebrospinal fluid biomarker for bacterial and viral central nervous system infections. J. Infect. Dis. 220, 127-138. doi: 10.1093/ infdis/jiz048

Sun, M., Gao, X., Zhang, D., Ke, C., Hou, Y., Fan, L., et al. (2013). Identification of biomarkers for unstable angina by plasma metabolomic profiling. Mol. Biosyst. 9:3059. doi: 10.1039/c3mb70216b

Takahashi, H., Kaihara, M., and Pricet, J. M. (1956). The conversion of kynurenic acid to quinaldic acid by humans and rats. J. Biol. Chem. 223, 705-708.

Takikawa, O., Yoshida, R., Kido, R., and Hayaishi, O. (1986). Tryptophan degradation in mice initiated by indoleamine 2,3-dioxygenase. J. Biol. Chem. 261, 3648-3653.

Tompsett, S. L. (1959). The determination in urine of some metabolites of tryptophan-kynurenine, anthranilic acid and 3-hydroxyanthranilic acid-and reference to the presence of o-aminophenol in urine. Clin. Chim. Acta 4, 411-419. doi: 10.1016/0009-8981(59)90112-3

Turner, M. R., Bowser, R., Bruijn, L., Dupuis, L., Ludolph, A., McGrath, M., et al. (2013). Mechanisms, models and biomarkers in amyotrophic lateral sclerosis. Amyotroph. Lateral Scler. Frontotemporal Degener. 14(Suppl. 1), 19-32. doi: 10.3109/21678421.2013.778554

Turner, M. R., Grosskreutz, J., Kassubek, J., Abrahams, S., Agosta, F., Benatar, M., et al. (2011). Towards a neuroimaging biomarker for amyotrophic lateral sclerosis. Lancet Neurol. 10, 400-403. doi: 10.1016/S1474-4422(11)70049-7
Turner, M. R., Kiernan, M. C., Leigh, P. N., and Talbot, K. (2009). Biomarkers in amyotrophic lateral sclerosis. Lancet Neurol. 8, 94-109. doi: 10.1016/S14744422(08)70293-X

Verdin, E. (2015). NAD+ in aging, metabolism, and neurodegeneration. Science 350, 1208-1213. doi: 10.1126/science.aac4854

Wang, M., Dong, X., Huang, Y., Su, J., Dai, X., Guo, Y., et al. (2019). Activation of the kynurenine pathway is associated with poor outcome in Pneumocystis pneumonia patients infected with HIV: results of 2 ?months cohort study. $B M C$ Infect. Dis. 19:223. doi: 10.1186/s12879-019-3851-4

Weiner, J., Parida, S. K., Maertzdorf, J., Black, G. F., Repsilber, D., Telaar, A., et al. (2012). Biomarkers of inflammation, immunosuppression and stress are revealed by metabolomic profiling of tuberculosis patients. PLoS One 7:e40221. doi: 10.1371/journal.pone.0040221

Weishaupt, J. H., Bartels, C., Pölking, E., Dietrich, J., Rohde, G., Poeggeler, B., et al. (2006). Reduced oxidative damage in ALS by high-dose enteral melatonin treatment. J. Pineal Res. 41, 313-323. doi: 10.1111/j.1600-079X.2006.00377.x

Widner, B., Leblhuber, F., and Fuchs, D. (2002). Increased neopterin production and tryptophan degradation in advanced Parkinson's disease. J. Neural Transm. 109, 181-189. doi: 10.1007/s007020200014

Xie, H., Hou, Y., Cheng, J., Openkova, M. S., Xia, B., Wang, W., et al. (2017). Metabolic profiling and novel plasma biomarkers for predicting survival in epithelial ovarian cancer. Oncotarget 8, 32134-32146. doi: 10.18632/oncotarget. 16739

Yoon, N. S., Cho, Y., Lee, S. Y., Choi, H. J., and Hwang, O. (2010). Inactivation of aconitase by Tetrahydrobiopterin in DArgic Cells: relevance to PD. Exp. Neurobiol. 19, 23-29. doi: 10.5607/en.2010.19.1.23

Young, P. E., Jew, S. K., Buckland, M. E., Pamphlett, R., and Suter, C. M. (2017). Epigenetic differences between monozygotic twins discordant for amyotrophic lateral sclerosis (ALS) provide clues to disease pathogenesis. PLoS One 12:e0182638. doi: 10.1371/journal.pone.0182638

Yuwiler, A., Oldendorf, W. H., Geller, E., and Braun, L. (1977). Effect of albumin binding and amino acid competition on tryptophan uptake into brain. J. Neurochem. 28, 1015-1023. doi: 10.1111/j.1471-4159.1977.tb10664.x

Zhang, X., Beaulieu, J.-M., Gainetdinov, R. R., and Caron, M. G. (2006). Functional polymorphisms of the brain serotonin synthesizing enzyme tryptophan hydroxylase-2. Cell. Mol. Life Sci. 63, 6-11. doi: 10.1007/s00018-005-5417-4

Zhang, Y., Cook, A., Kim, J., Baranov, S. V., Jiang, J., Smith, K., et al. (2013). Melatonin inhibits the caspase-1/cytochrome c/caspase- 3 cell death pathway, inhibits MT1 receptor loss and delays disease progression in a mouse model of amyotrophic lateral sclerosis. Neurobiol. Dis. 55, 26-35. doi: 10.1016/J.NBD. 2013.03.008

Zhao, J. (2013). Plasma Kynurenic Acid/Tryptophan Ratio: a sensitive and reliable biomarker for the assessment of renal function. Ren. Fail. 35, 648-653. doi: 10.3109/0886022X.2013.790301

Zinellu, A., Fois, A. G., Zinellu, E., Sotgiu, E., Sotgia, S., Arru, D., et al. (2018). Increased kynurenine plasma concentrations and kynurenine-tryptophan ratio in mild-to-moderate chronic obstructive pulmonary disease patients. Biomark. Med. 12, 229-237. doi: 10.2217/bmm-2017-0280

Zuo, H., Ueland, P. M., Ulvik, A., Eussen, S. J. P. M., Vollset, S. E., Nygård, O., et al. (2016). Plasma biomarkers of inflammation, the kynurenine pathway, and risks of all-cause, cancer, and cardiovascular disease mortality. Am. J. Epidemiol. 183, 249-258. doi: 10.1093/aje/kwv242

Conflict of Interest: The authors declare that the research was conducted in the absence of any commercial or financial relationships that could be construed as a potential conflict of interest.

Copyright (C) 2019 Tan and Guillemin. This is an open-access article distributed under the terms of the Creative Commons Attribution License (CC BY). The use, distribution or reproduction in other forums is permitted, provided the original author(s) and the copyright owner(s) are credited and that the original publication in this journal is cited, in accordance with accepted academic practice. No use, distribution or reproduction is permitted which does not comply with these terms. 